\title{
Rumo à Gestão Estratégica de Recursos Humanos? Estudo de Caso em uma Organização Pública Paulista
}

\author{
Wesley Ricardo de Souza Freitas ${ }^{1}$ \\ Charbel José Chiappetta Jabbour ${ }^{2}$
}

\section{Resumo}

O objetivo deste artigo é analisar as principais características das práticas de Recursos Humanos numa organização pública paulista, além de procurar responder à questão: a gestão de Recursos Humanos na organização Y é compatível com os atuais paradigmas dessa área de gestão, considerados mais estratégicos? Para realização desta pesquisa, adotou-se uma abordagem qualitativa, através do estudo de caso. Os dados primários foram obtidos através de entrevistas informais e dados secundários foram obtidos através da análise de informações e documentos disponibilizados no site da organização e também da observação direta da rotina organizacional. Os resultados alcançados indicam que, apesar da organização utilizar a denominação "administração estratégica de Recursos Humanos", apresenta uma abordagem voltada para a administração dos aspectos legais $e$ operacionais da área. As práticas de recursos humanos encontram-se desintegradas $e$ algumas inexistem dentro de uma perspectiva sistêmica (plano de carreira e treinamento). $\mathrm{O}$ artigo registra diversas propostas para que a organização analisada tenha uma gestão de recursos humanos mais estratégica. Acredita-se que se a organização adotar algumas das melhorias propostas neste artigo estará caminhando rumo à modernização de sua gestão $e$ inserindo-se no novo contexto da nova gestão pública.

Palavras-chave: Gestão de Recursos Humanos. Setor público. Gestão estratégica.

\section{Introdução}

Nas últimas décadas, o fator humano vem sendo considerado um diferencial e um dos pilares que sustentam o desempenho das organizações. Práticas modernas de gestão de Recursos Humanos (GRH) são observadas

\footnotetext{
${ }^{1}$ Mestre em Engenharia de Produção pela UNESP-Bauru/SP. Endereço: UNESP-Bauru/SP, Av. Eng. Carrijo Coube, s/n, Bauru, SP - Brasil, CEP: 17.033-360.E-mail: wesley007adm@yahoo.com.br.

${ }^{2}$ Doutor em Engenharia de Produção pela USP. Professor Doutor da FEA-USP/Campus Ribeirão Preto. Endereço: Av. Bandeirantes, 3900 , Ribeirão Preto, SP-Brasil, CEP 14.040-905.E-mail: charbel@usp.br.
} 
em muitas organizações, que passaram a considerar as pessoas como essencial para garantir melhores resultados e colocam a GRH no centro da sustentabilidade organizacional (JABBOUR; SANTOS, 2008). Como ficam as organizações públicas, diante dessas novas tendências na gestão de Recursos Humanos?

Tradicionalmente, a gestão de Recursos Humanos no setor público é tratada apenas sob um aspecto legal e operacional que visa atender apenas às questões legais, e que segundo Marconi (2003), apresenta duas funções básicas: processamento das atividades administrativas e a proposição de leis, regras e outros regulamentos relativos ao tema. Para o autor, a área caracterizase por priorizar tarefas rotineiras, relegando atividades estratégicas, como definição de políticas para recrutamento, qualificação, desenvolvimento $e$ remuneração, para um segundo plano devido ao excesso de regulamentação e a falta de autonomia, que imobilizam ações inovadoras para a gestão de Recursos Humanos do setor público.

Nogueira e Santana (2001, p. 14) destacam que

[...] vivemos um momento em que, de todos os lados, surgem sinais de que a importância da gestão de Recursos Humanos está sendo reavaliada, inclusive esta tendência aparece também nas iniciativas de reforma do setor público.

É unânime entre acadêmicos, profissionais do setor público e, principalmente, a sociedade que as organizações públicas precisam adotar uma postura mais eficiente e eficaz, orientada pela satisfação dos cidadãos (GONZÁLEZ; GIDUMAL, 2009), a fim de cumprir seu papel social e sua missão. Para tanto, torna-se necessário possuir em seus quadros servidores capacitados e motivados, que prezem pela melhoria contínua e pela excelência na prestação dos serviços, conseguindo assim cumprir os objetivos organizacionais e contribuindo efetivamente com a missão da organização pública.

Tais resultados só serão alcançados a partir da modernização da gestão das organizações públicas (GONZÁLEZ; GIDUMAL, 2009), através do desenvolvimento de uma GRH flexível e aberta às inovações, com capacidade de adaptar-se aos novos paradigmas, que valorize o fator humano, dando maior ênfase aos resultados, e que procure integrar as contribuições da área de $\mathrm{RH}$ à estratégia organizacional. 
Dessa forma, o objetivo deste artigo é analisar as principais características das práticas de Recursos Humanos (recrutamento e seleção, treinamento e desenvolvimento, remuneração, avaliação de desempenho, plano de carreira e rotina de pessoal) em uma organização pública paulista, além de procurar responder à questão proposta neste estudo: a gestão de Recursos Humanos na organização Y é compatível com as atuais tendências de gestão de Recursos Humanos?

Adiantam-se ao leitor as seções deste artigo: a seção 2 trata da gestão estratégica de Recursos Humanos; a Seção 3 apresenta os subsistemas da GRH; na seção 4, é destacada a gestão estratégica de Recursos Humanos no contexto do setor público; na seção 5 , apresentam-se os procedimentos metodológicos adotados; na seção 6, apresentam-se as práticas adotadas pela organização estudada, bem como a análise do caso, e, por fim, são apresentadas as considerações finais e algumas sugestões de estudo.

\section{Gestão Estratégica de Recursos Humanos}

A administração de Recursos Humanos é resultado do desenvolvimento empresarial e da evolução da teoria organizacional nos Estados Unidos. Ela veio para superar a tradicional visão de departamento de pessoal, que se caracteriza por realizar as atividades burocráticas da organização (FISCHER, 2002). O grande desafio para a GRH no atual contexto é conseguir integrar as pessoas com as políticas e objetivos da organização (BELOUT; DOLAN; SABA, 2001).

Milkovich e Boudreau (2006, p. 19) entendem a GRH como

[...] uma série de decisões integradas que formam as relações de trabalho; sua qualidade influencia diretamente a capacidade da organização e de seus agentes em atingir seus objetivos.

Roknuzzaman (2007) complementa que esses agentes estão envolvidos em qualquer configuração organizacional para cumprir determinados objetivos.

O fator estratégico no contexto da gestão de Recursos Humanos surgiu porque se percebeu que uma organização gerenciada estrategicamente pode 
desfrutar de vantagens competitivas de longo prazo (KHATRI, 1999; PABLOS; LYTRAS, 2008) e o pressuposto fundamental que sustenta essa argumentação é que o conjunto das práticas de $\mathrm{RH}$ pode influenciar o desempenho organizacional (HUSELID; JACKSON; SCHULER, 1997). A gestão estratégica de Recursos Humanos (GERH) deve facilitar a flexibilidade estratégica com o objetivo de alcançar um ajuste dinâmico entre a estratégia organizacional e o ambiente, de modo que a área deve explorar a integração dos recursos, das práticas e capacidades organizacionais, a fim de facilitar a realização das vantagens competitivas para a organização (PABLOS; LYTRAS, 2008). É um modelo que exige interpretação e adaptação pelos praticantes, a fim de assegurar a mais adequada ligação entre as estratégias de $\mathrm{RH}$, estratégias e planos organizacionais, exigindo o alinhamento de todas as práticas de Recursos Humanos aos objetivos organizacionais, o que permite maior capacidade de resposta ao ambiente externo (WORLAND; MANNING, 2005).

As tradicionais práticas e políticas em gestão de Recursos Humanos devem ser revisadas e integradas em um sistema consistente, em que as estratégias da organização sejam capazes de influenciar e ser influenciadas pelas estratégias de Recursos Humanos (SAMMARTINO, 2002). Além disso, dentro do contexto estratégico, as tradicionais práticas de Recursos Humanos ganham novas estratégias, como a utilização ferramentas tecnológicas nos processos de recrutamento, avaliação de desempenho e treinamento, por exemplo, de maneira que interajam entre si e complementem-se nos processos de gestão de Recursos Humanos.

Apesar de ser notório que o investimento no fator humano é requisito fundamental para garantir sustentação de qualquer negócio, muitas organizações, especialmente as públicas, ainda configuram suas áreas de Recursos Humanos apenas para registrar e operacionalizar a rotina administrativa, voltando-se para o controle das pessoas, buscando a redução de custos, na qual seu foco é voltado para os números, mantendo a força de trabalho estreitamente alinhada com os requisitos técnicos (AHMED; KAZMI, 1999; WORLAND; MANNING, 2005), assemelhando-se a uma abordagem mecanicista, na qual se considera as pessoas como "peças intercambiáveis" dentro de um sistema produtivo (HARRIS, 1999, p. 55). 


\section{Os Subsistemas (práticas) da Gestão de Recursos Humanos}

\subsection{Recrutamento e Seleção}

Recrutamento e seleção são atividades indispensáveis para as organizações, apresentando "grande quantidade de instrumentos comprovados cientificamente, que proporcionam melhor qualidade e maior precisão a esses processos" (FRANÇA; ARELLANO, 2002, p. 63), e que além de trazer novos funcionários, é o momento de selecionar as pessoas certas, separando os não adequados antes de "entrarem pela porta, não depois" (DESSLER, 2003, p. 106).

A contratação de novos funcionários é uma das estratégias principais para atingir o perfil ideal de profissionais para composição dos quadros das organizações públicas, constituindo-se na porta de entrada, muitas vezes permanente no serviço público, e por este motivo, tal processo deve ser realizado de forma muito precisa (MARCONI, 2003). É através do processo de recrutamento que a organização expõe o grau de profissionalismo em relação à gestão de pessoas e um processo de recrutamento mal conduzido projeta uma imagem negativa da organização; e diversamente, uma organização que é reconhecida como um bom lugar para trabalhar terá maior visibilidade e provavelmente maior número de candidatos (FRANÇA; ARELLANO, 2002) e maiores chances de escolher as pessoas mais adequadas para realização dos objetivos.

Santos (1973 apud FRANÇA; ARELLANO, 2002, p. 66) define seleção de pessoal como:

[...] é um processo pelo qual são escolhidas pessoas adaptadas à determinada ocupação ou esquema operacional. Nem sempre isso significa escolher candidatos que revelam aptidões ou capacidades em índices elevados. Em princípio, é a escolha dos candidatos com maior afinidade de expectativas $e$ potencialidades com as expectativas $e$ necessidades previstas para o cargo ou posição em processo de preenchimento. Isso significa aqueles que mais convêm a determinado plano de ação, pois em muitos casos os escolhidos não são os mais talentosos, e sim os mais adequados a uma função em uma situação predeterminada. 


\subsection{Treinamento e Desenvolvimento}

O ambiente dinâmico das organizações requer o desenvolvimento de ações voltadas à constante capacitação das pessoas, com o objetivo de tornálas mais eficazes naquilo que fazem (GIL, 2006) e a chamada área de T \& D "foi criada com o intuito de que as pessoas da organização pudessem ser mais bem capacitadas a ocupar determinadas posições na organização e/ou desenvolver seu potencial na posição ocupada" (ARAÚJO, 2006, p. 92). De todas as práticas de Recursos Humanos, a gestão de treinamento e desenvolvimento é a mais importante para integrar as pessoas aos valores e objetivos organizacionais (ALBERT; SILVERMAN, 1984).

Borges-Andrade (2002) define treinamento como ação organizacional planejada, que possibilita a aquisição de habilidades técnicas e comportamentais, assim como contribui com o desenvolvimento de estratégias cognitivas que podem tornar o indivíduo mais apto a desempenhar suas funções atuais ou futuras.

Desenvolvimento de Recursos Humanos consiste numa série de atividades organizadas, realizadas dentro de um determinado tempo $e$ destinadas a produzir mudanças comportamentais, através de ações de formação "aprendizagem presente - para o trabalho) e educação (aprendizagem futura - empregabilidade" (NADLER apud HARRIS, 1999, p. 56), além de desenvolver nas pessoas "as habilidades mais amplas necessárias as suas funções atuais e futuras" (BATEMAN; SNELL, 1998, p. 288).

Dentro do contexto da administração pública não é diferente. A capacitação, através das estratégias de treinamento e desenvolvimento, também é componente fundamental no processo de construção do perfil ideal de pessoas para os órgãos públicos (MARCONI, 2003).

\subsection{Remuneração}

O termo refere-se a "todos os pagamentos monetários e todos os bens ou mercadorias usados para recompensar empregados" (DAFT, 1999, p. 263). As decisões sobre a estruturação e o funcionamento do subsistema de recompensas e seu gerenciamento no dia a dia organizacional constituem uma das dimensões mais críticas em gestão de pessoas (HIPOLITO, 2002). Para o autor, historicamente, o principal critério para definição do salário é o cargo ocupado, que na prática reúne diferenciações em função do nível de 
maturidade exigido, tempo de atuação na organização e conjunto de conhecimento ou habilidades.

Dentro da administração pública, Marconi (2003, p. 11) afirma que:

[...] nas discussões atuais sobre remuneração dos servidores públicos, o parâmetro básico para a definição das correções salariais tem sido a remuneração para cargos equivalentes no setor privado, observada novamente a restrição estabelecida pela disponibilidade orçamentária. Adicionalmente, outra questão importante a observar é a recuperação da hierarquia salarial, isto é, da consistência da estrutura de salários relativos, baseada na complexidade das atribuições, responsabilidades e competências. A hierarquia é importante para evitar o desestímulo por parte dos servidores, enquanto o pagamento de remunerações compatíveis com as praticadas no setor privado é fundamental para permitir a comunicação entre os mercados de trabalho público e privado e, por conseqüencia, o recrutamento de servidores qualificados, bem como implica em maior justiça tanto para os funcionários como para a sociedade que em última instância financia os salários pagos no setor público.

De acordo com Seabra (2001), a mudança mais significativa no sistema de remuneração relacionado às organizações públicas, foi a introdução da gratificação de desempenho e produtividade (GDP). Segundo o autor, essa gratificação representa um percentual do salário base do profissional, a ser pago segundo as performances individuais e institucionais, ou seja, o salário do profissional depende não somente de seu desempenho individual, mas também do desempenho e dos resultados do seu setor de trabalho e da organização, que pode ser considerado um instrumento de incentivo concebido tanto para motivar as pessoas na realização das suas atividades quanto para manter as metas individuais compatíveis com os objetivos gerais da organização.

\subsection{Avaliação de Desempenho}

Segundo Hipólito e Reis (2002, p. 73)

[...] pronunciar o termo avaliação é o suficiente para remeter as pessoas quase instantaneamente a tal instrumen- 
to, cujo propósito é verificar quanto o profissional se adapta aos objetivos da empresa e às demandas e exigências do trabalho [...] além de produzir implicações importantes em termos de remuneração e carreira.

As avaliações podem ser definidas como um processo que visa determinar os resultados do trabalho de um funcionário e uma de suas principais funções é oferecer uma justificativa para a compensação dos resultados e esforços dos funcionários (TÜRK; ROOLAHT, 2007, p. 207).

Avaliação de desempenho é um processo formalizado para classificar o desempenho atual do funcionário (STONER; FREEMAN, 1999), além de ser

[...] utilizada para tomar decisões fundamentais relativas às pessoas, tais como promoções, transferências e rescisões; para identificar as necessidades de treinamento; para dar feedback aos funcionários sobre como a organização encara seu desempenho e, freqüentemente é utilizada como base para os reajustes salariais (ROBBINS; DECENZO, 2004, p. 246).

Com tal instrumento, pode-se apoiar as pessoas e a organização na consecução do desempenho máximo (CHOW, 2004), além de sustentar as ações dos gestores; nortear o processo de treinamento e desenvolvimento, facilitar o feedback para as pessoas e o progresso da organização (ARAÚJO, 2006).

Para Marconi (2003), uma política de avaliação de desempenho representa uma ferramenta importante para o desenvolvimento de uma cultura voltada para resultados no setor público. Para o autor, o alinhamento de objetivos individuais e das equipes às metas organizacionais implica em maior envolvimento dos funcionários de todos os níveis, os quais passam a se sentir pessoalmente responsáveis pelo desempenho da organização.

\subsection{Plano de Carreira}

Na definição do sistema de administração de carreiras, as decisões sobre a configuração técnica do sistema devem estar alinhadas com a definição estratégica, e para tanto o sistema deve apresentar: formatação e características das estruturas de carreira, níveis (degraus) dentro de cada estrutura e requisitos de acesso e escolha dos instrumentos de gestão no sistema (DUTRA, 2002). 
Uma estrutura de progressão adequada para as carreiras, no setor público, é fundamental porque suas características definem a forma e os incentivos ao desenvolvimento profissional do servidor. As regras devem associar a ascensão do funcionário ao acúmulo de novas competências, atribuições e ao seu desempenho, isto é, à sua formação, ao desenvolvimento de habilidades necessárias à realização de determinadas tarefas, à sua experiência e ao processo de avaliação e, por decorrência, à possibilidade de assumir novas responsabilidades (MARCONI, 2003).

As carreiras surgem das interações entre as aspirações dos funcionários, suas escolhas e as oportunidades disponibilizadas pela organização (MILKOVICH; BOUDREAU, 2000) $e$

[...] não devem ser entendidas como uma moldura na qual as pessoas devam obrigatoriamente se encaixar, mas como uma estruturação de opções, uma forma de organizar possibilidades como suporte para que a pessoa planeje sua carreira na empresa (DUTRA, 2002, p. 47)

e quanto mais ampla as trajetórias da carreira, maiores habilidades o funcionários precisa adquirir para poder contribuir com diversas áreas funcionais e com as estratégias organizacionais (SCHULER; JACKSON, 1987).

No atual contexto, um plano de carreira bem construído é fundamental para a retenção e motivação das pessoas, além de ser uma ferramenta que permite alinhar claramente os objetivos individuais aos objetivos organizacionais, através do alinhamento da carreira aos resultados do negócio.

\subsection{Rotinas de Pessoal}

A área responsável pela rotina administrativa e de pessoal é o chamado departamento de pessoal, que muitos confundem com a GRH, e que Marras (2000) destaca que seu objetivo é efetivar todos os registros legais e necessários para a administração burocrática exigida pelas práticas administrativas e pela legislação que rege a relação capital e trabalho.

No setor público, a gestão estratégica de Recursos Humanos deve consistir na integração da política de Recursos Humanos à política organizacional, contribuindo com o sucesso da missão de qualquer organização pública: prestar serviços à sociedade com extrema qualidade e eficiência. 


\section{Gestão Estratégica de Recursos Humanos no Setor Público}

Um dos problemas crônicos do setor público brasileiro é a predominância de estruturas com excessivos níveis hierárquicos e departamentos. Isso gera lentidão administrativa, comunicação formal, burocrática e lenta, além de serviços e produtos que não satisfazem à população (BATISTA et al., 1996) e tradicionalmente, os estímulos para que os profissionais sejam atraídos para a área pública estão relacionados à estabilidade, segurança, aumento de salário de acordo com o tempo de serviço, não havendo necessidade de melhorias no trabalho para obtê-los, bastando permanecer no cargo (MARCONI, 2003).

Durantes as décadas de 1980 e 1990, a setor público passou por inúmeras reestruturações (FAIRBROTHER, 1996) e tem sofrido pressões para mudar seu modo de gestão (MORLEY, 1993 apud MACKAY, 1995; WILLIANS, 2004). A crescente valorização da área de Recursos Humanos nas últimas décadas repercutiu principalmente no setor privado, e apenas recentemente começou a se expandir, mesmo que lentamente, no contexto do setor público (GAETANI; BAGGIO, 1997), sendo que o maior desafio e ao mesmo tempo a maior oportunidade para a área de $\mathrm{RH}$ obter destaque no setor público consiste em adquirir um estilo de gestão gerencial mais estratégico e eficaz (LAVELLE, 2005).

FairBrother (1996), Boyne, Jenkins e Poole (1999), Seabra (2001) concordam com o pressuposto de que a gestão de Recursos Humanos no setor público está adotando um enfoque mais profissional, um estilo de gestão gerencial similar à aplicada pelo setor privado, onde o empirismo está dando espaço para uma gestão profissionalizada, focada na qualidade, com maior espírito de cooperação e uma maior orientação para as necessidades do cidadão.

Porém, em relação às rápidas mudanças que são observadas na gestão das empresas privadas, como introdução práticas como remuneração por habilidades, avaliações de desempenho tipo 360 graus, formação de equipes, gestão por competências, o setor público ainda encontra-se bastante "refratário a toda esta movimentação" (GAETANI; BAGGIO, 1997, p. 2), sendo que as evidências empíricas da gestão estratégica de recursos humanos são quase que inexistentes no setor público (WORLAND; MANNING, 2005).

Para Thompson (1998 apud WILLIANS, 2004) há provas claras de que a adoção dessas práticas inovadoras de gestão de Recursos Humanos, como 
a gestão estratégica, está associada a um desempenho organizacional mais eficaz; e o novo modelo de administração pública vem incorporando princípios de eficiência, descentralização e busca da excelência na prestação do serviço público (AYRES, 2006). Essas práticas destacadas por Gaetani e Baggio (1997), Thompson (1998) e Ayres (2006) podem ser enquadradas no conceito de Nova Gestão Pública. Segundo González e Gidumal (2009), uma das principais características desse modelo é a utilização de práticas de gestão típicas do setor privado.

Analisando o Relatório Mundial do Setor Público de 2005, Lavelle (2005, p. 218) observou que os exemplos mais conhecidos dessa nova gestão pública são encontrados na Austrália, Nova Zelândia e Reino Unido. Para o autor, na Irlanda e na Nova Zelândia, a questão da antiguidade no cargo já não é mais considerada como único fator de progressão ou promoção para níveis mais altos, enquanto na África do Sul, existe uma grande dificuldade na retenção de talentos, devido à crescente competitividade no setor privado, que oferece melhores oportunidades de carreira.

Ayres (2006) salienta que a adoção, pelo setor público, da orientação gerencial configura-se numa das mais importantes providências administrativas tomadas pelos dirigentes públicos, nesta nova fase da administração pública, que busca a modernização do Estado com o objetivo de cumprir seu papel perante a sociedade. Essa mesma ideia é compartilhada por Fairbrother (1996) que destaca que o Estado tem estimulado a rejeição das formas tradicionais da gestão pública e da organização do trabalho, promovendo práticas gerenciais associadas com formas flexíveis de trabalho, bem como a introdução de modernas técnicas de gestão.

No Irã, as organizações públicas são mais preocupadas com temas relacionados à gestão de Recursos Humanos do que a maioria das pequenas e médias empresas, que caracterizam pela gestão familiar e que não dependem de políticas formais de Recursos Humanos para sua gestão, e apesar disso, a GRH no setor público iraniano ainda está na fase de gestão de pessoal e pouca atenção é dada à eficiência organizacional (YEGANEH; SU, 2008).

O Governo Britânico vem mostrando interesse na valorização dos Recursos Humanos. Em 2003, o Departamento de Comércio e Indústria criou a Contabilização de Pessoas para influenciar as organizações públicas a apresentarem um relatório sobre o desempenho da área em quatro dimensões: a dimensão e a composição da força de trabalho; emprego de práticas de motivação, formação e desenvolvimento de pessoal; 
e remuneração (VERMA; DEWE, 2008, p. 105). Segundo os autores, o governo inglês acredita que a competência e o empenho dos trabalhadores são importantes para a criação de valor para as organizações.

Chow (2004, p. 629) destaca que as constantes reformas das organizações públicas em Hong Kong levaram à flexibilidade e à adoção de algumas das melhores práticas de RH de organizações ocidentais, devido à grande concentração de multinacionais no país, o que facilitou a transferência e o desenvolvimento das melhores práticas em gestão de pessoas nas organizações pública do país.

A administração pública Japonesa conjuga tradicionalismo e forte ênfase à hierarquia com iniciativas inovadoras de gestão de Recursos Humanos, como a reestruturação organizacional, que diminuiu o número de Ministérios, reformulou o processo de seleção, redefiniu as políticas de compensação, promoveu práticas de capacitação em cooperação como o setor privado $e$ criou um sistema de avaliação por desempenho (KOGA, 2007, p. 99). A autora destaca que algumas medidas estão sendo realizadas pelo governo japonês, como a melhoria das condições de trabalho para os servidores públicos que tenham filhos (como concessão de indenizações, horas reduzidas de trabalho e creches), extensão da idade de aposentadoria compulsória de 60 para 65 anos, planos de trabalho especiais para servidores aposentados e incentivos para as mulheres que retornam ao trabalho após terem filhos. Em Cingapura, o governo tem incentivado os gestores das organizações públicas a adotar técnicas que promovam o desenvolvimento dos Recursos Humanos (KHATRI, 1999).

No Estado de Michigan, EUA, as pressões legais, políticas e tecnológicas, além da pressão pela adoção de um sistema avançado de informações de $\mathrm{RH}$, e a própria pressão em cima dos profissionais para exercerem um papel consultivo, ajudou a impulsionar as melhorias na gestão de pessoas, a fim de atingir a eficácia e eficiência (MOTHERSELL et al., 2008). Os autores verificam que o Estado de Michigan atua com ações, através de um programa que visa desenvolver gestores de Recursos Humanos e que tem como o objetivo aumentar a eficácia dos programas e serviços da área, além de promover uma abordagem consultiva, desenvolver os Recursos Humanos como um parceiro estratégico das organizações e atuando como agentes de mudanças na gestão das agências governamentais, além de criar a capacidade de incorporar as melhores práticas de $\mathrm{RH}$. A partir destas ações nasceu no Estado de Michigan a Academia de Formação e Desenvolvimento de Recursos Humanos, para fornecer ao Estado profissionais capacitados para 
atingir a nova visão que o Estado desejava possuir e para atender às áreas mais carentes de profissionais.

Todas essas iniciativas nos setores públicos na Inglaterra, no Irã, Japão, Hong Kong, Cingapura e nos Estados Unidos evidenciam a evolução da GRH no setor público, adotando uma gestão gerencial e profissionalizada.

A gestão de Recursos Humanos em organizações públicas no Brasil, salvo raras exceções, ainda não incorporou essas questões e o fator humano como um pressuposto para a excelência organizacional, melhorando os serviços públicos, tanto na área da saúde, educação e segurança pública.

\section{Procedimentos Metodológicos}

A pesquisa foi realizada em uma organização pública estadual, doravante chamada de organização "Y", localizada no interior do Estado de São Paulo, que conta com aproximadamente 550 servidores públicos. Escolheu-se a organização para o estudo tendo em vista a sua importância social e econômica para a região, além do significativo quadro de pessoal.

Para alcançar o objetivo proposto, adotou-se uma abordagem qualitativa, segundo Godoy (1995, p. 58). Liebscher (1998) ressalta que a abordagem qualitativa é adequada quando o fenômeno em estudo é complexo, de natureza social e é de difícil quantificação, e normalmente é utilizado para compreensão do contexto social. Para responder ao problema proposto, o estudo de caso foi o método adotado, apropriado para a condução desta pesquisa e mais próximo à sugestão de Hesketh e Fleetwood (2006) que fazem um apelo para a utilização de entrevistas e estudos de casos, a fim de desvendar as causas subjacentes e inter-relacionadas das práticas de Recursos Humanos.

O propósito de um estudo de caso é reunir informações detalhadas e sistemáticas sobre um fenômeno (PATTON, 2002), é um procedimento metodológico que enfatiza entendimentos contextuais (LLEWELLYN; NORTHCOTT, 2007) e centra-se na compreensão da dinâmica do contexto (EISENHARDT, 1989) e que envolve um estudo profundo e exaustivo de um ou poucos objetos, de maneira que se permita o seu amplo e detalhado conhecimento (GIL, 2007). 
Martins (2008, p. 11) ressalta que

[...] mediante um mergulho profundo e exaustivo em um objeto delimitado, o estudo de caso possibilita a penetração em uma realidade social, não conseguida plenamente por um levantamento amostral e avaliação exclusivamente quantitativa

Um dos grandes benefícios desse método é a possibilidade do desenvolvimento de uma nova teoria e o aumento do entendimento sobre os eventos reais contemporâneos (MIGUEL, 2007).

Como instrumento de coleta de dados foi utilizado um roteiro, construído em com base no referencial teórico e que forneceu o embasamento necessário para o levantamento de evidências na organização, através de entrevistas junto aos profissionais da organização e que versaram sobre as práticas de Recursos Humanos: recrutamento, seleção, avaliação de desempenho, treinamento, desenvolvimento, remuneração, plano de carreira e rotinas de pessoal.

Foram realizadas entrevistas com funcionários que trabalham na área de Recursos Humanos, além da obtenção de dados secundários obtidos através da análise de informações e documentos disponibilizados no site da organização e observação direta da rotina organizacional, por aproximadamente noventa dias. Justifica-se entrevistar os funcionários da área em razão do conhecimento aprofundado em relação às práticas de gestão de Recursos Humanos da organização objeto de estudo.

Em relação à análise dos dados, Eisenhardt (1989) destaca que não existe um padrão ou um formato para análise de dados em pesquisas conduzidas através dos procedimentos de estudo de caso, é a etapa mais difícil e a menos codificada do processo. Borges, Hoppen e Luce (2009, p. 886) conceituam a análise em "examinar, categorizar, tabular e recombinar os elementos de prova, mantendo o modelo conceitual e as proposições iniciais do estudo como referências".

Para análise de resultados, os dados empíricos foram sistematizados com base nas variáveis da fundamentação teórica previamente apresentada. Então, foram observados padrões de comportamento dessas variáveis, posteriormente comparadas aos fundamentos teóricos. 


\section{Análise e Discussão dos Resultados}

\subsection{Subsistemas de Recursos Humanos da Organização Y}

O processo de recrutamento pode ser considerado satisfatório. Quando uma vaga é aberta, além da divulgação através da imprensa oficial do Estado, também é amplamente divulgado em rádios e jornais da região, como também é disponibilizado na Internet e em Sites específicos de concurso público, o que aumenta a amplitude de divulgação do processo de seleção $e$, conseqüentemente, aumenta a quantidade de candidatos, proporcionando desta maneira, melhor chance de acerto na escolha do candidato em relação às exigências do cargo. A organização $Y$ apresenta uma defasagem no aspecto quantitativo do quadro de funcionários, devido principalmente à aposentadoria de muitos servidores, não existindo um planejamento para suprir essa necessidade de forma rápida. Destaca-se que essa é uma característica típica do setor público.

O processo de seleção ocorre através de provas escritas, práticas ou de títulos. Todo esse processo de atração e seleção de candidatos ocorre através de concurso público. É uma forma democrática, porém, pouco efetiva em relação às características comportamentais, como trabalho em equipe, iniciativa, liderança, valores e comprometimento. Outro ponto deficiente no processo de seleção da organização Y é que, algumas vezes, são admitidas pessoas com expectativas maiores do que o cargo pode oferecer. Isto acontece porque na seleção através de concursos públicos são escolhidos os candidatos que tiveram melhor desempenho nas provas e não os mais adequados ao cargo a ser preenchido, o que vai contra a argumentação de Dessler (2003) de que o processo de seleção é um momento crucial para a organização selecionar as pessoas que querem se comprometer com a organização e não depois, num futuro processo de avaliação de desempenho.

A organização estudada contraria a argumentação de Albert e Silverman (1984) e não reserva qualquer percentual de seus recursos orçamentários para as práticas de treinamento e desenvolvimento. Não apresenta um programa formal de integração e de desenvolvimento para os funcionários recém admitidos. A capacitação dos funcionários acontece de forma esporádica, são realizadas ações conforme vão surgindo às necessidades, o que contraria as argumentações de Borges-Andrade (2002) de que o treinamento é uma ação organizacional planejada de modo sistemático e de 
Nadler (apud HARRIS, 1999, p. 56) de que o desenvolvimento consiste numa série de atividades organizadas, a fim de conduzir a mudanças comportamentais.

A remuneração é estruturada de forma tradicional, sendo que o critério principal para definição do salário é o cargo ocupado, o tempo de serviço e o grau de complexidade e responsabilidade, diferindo das afirmações de Seabra (2001), não existindo uma política de remuneração por desempenho, meta ou produtividade (individual ou grupal) ou por competência. A remuneração é reajustada quando o servidor preenche alguns requisitos conjuntos de tempo de serviço e ou quando aconteça uma promoção, o que gera apenas uma mudança na faixa salarial do servidor, podendo ser horizontal quanto vertical. De modo geral, o aumento da remuneração do servidor está atrelado ao tempo de permanência na organização.

A avaliação de desempenho está parcialmente de acordo com as argumentações de Robbins e Decenzo (2004), de que é utilizada para dar subsídios para as promoções e consequentemente progressões salariais. Predominantemente, prioriza esta utilização em detrimento a principal característica da avaliação de desempenho: detectar necessidades de treinamento e desenvolvimento.

No processo de avaliação, os fatores de desempenhos são elaborados a partir de critérios pré-estabelecidos, em conjunto pelo funcionário e pelo superior hierárquico. Teoricamente a avaliação apresenta uma metodologia mais moderna, onde alguns fatores de desempenho são definidos de comum acordo pelo avaliado e pelo avaliador, outros são determinados pela direção superior da instituição. Na realidade, o instrumento de avaliação de desempenho não possui todo seu potencial explorado. O formulário é disponibilizado de forma eletrônica, é extremamente igual para todos os cargos (não considerando as especificidades de cada cargo), tanto para um cargo de ensino fundamental quanto para um cargo nível superior, sendo que muitos funcionários não sabem utilizar microcomputador ou não entendem os termos técnicos utilizados.

Em relação a planos de carreira, a organização Y não explora o potencial desta prática. A carreira consiste numa progressão funcional através da política salarial. Não existe uma carreira desafiadora que estimule o desenvolvimento profissional, conforme destacaram Schuler e Jackson (1987). Na organização, o servidor só pode assumir novas responsabilidades e enfrentar novos desafios se for indicado para exercer uma posição de chefia 
e exercer uma função de confiança, caso contrário, permanecerá na mesma função, exercendo a mesma atividade, até se aposentar.

A grande ênfase da área de Recursos Humanos da organização estudada é nas rotinas de pessoal. Predominam os aspectos administrativos relacionados à folha de pagamento, controle de freqüencia, concessão de aposentadorias e controle de outros benefícios legais. O aspecto mais agravante é a falta de informatização e o excesso de regulamentação, o que acaba deixando o trabalho lento e burocratizado. Neste aspecto, as informações e dados sobre a vida funcional e financeira dos servidores são registrados e lançados manualmente em livros e planilhas. Sob o aspecto da frequência, utiliza-se um sistema moderno de controle de ponto, utilizando o ponto biométrico (leitura da digital) para o controle de entradas e saídas. No processo de folha de pagamento, a falta de informatização e a burocracia entravam à eficiência no atendimento em relação às necessidades dos servidores. Todo esse processo poderia ser simplificado se a organização possuísse um sistema informatizado onde fossem disponibilizadas as informações de interesse dos funcionários.

\subsection{Gestão Estratégica de Recursos Humanos na Organização Y}

De modo geral, a organização $\mathrm{Y}$ ainda não conseguiu alinhar a política de Recursos Humanos à estratégia organizacional, o que seria essencial, conforme argumentação de Belout, Dolan e Saba (2001). A missão da área de Recursos Humanos não é explicitada. Para que isso aconteça, além da revisão em suas práticas e processos relacionados à gestão de pessoas, seria necessária uma mudança cultural, através do reconhecimento de que o investimento no fator humano dará suporte para a consecução dos objetivos organizacionais.

É necessária a adoção de uma postura dinâmica, inovadora que crie um ambiente participativo e de constante crescimento, ou seja, é preciso ocorrer uma mudança cultural na organização, rompendo com o burocrático, adotando uma abordagem estratégica, que valorize o desempenho, o resultado, que concilie os objetivos individuais com os organizacionais e que contribua para um crescimento de longo prazo. Assim, estaria adotando uma gestão de Recursos Humanos com estilo de gestão mais estratégico, conforme destacaram FairBrother (1996), Boyne, Jenkins e Poole (1999), Seabra (2001), resguardando as especificidades das organizações públicas. 
As práticas na organização estão desintegradas umas das outras e das estratégias organizacionais, e a GRH pouco contribui para os resultados da organização (mesmo porque desconhece esses resultados), sendo que as políticas e práticas adotadas precisam ser revistas e integradas com a missão organizacional, conforme argumentações de Worland e Manning (2005) e Sammartino (2002).

Assim, ao analisar as limitações da gestão estratégica de recursos humanos na organização Y, apresentam-se alguns pontos a serem melhorados, conforme Quadro 1.

\begin{tabular}{|c|c|c|c|}
\hline $\begin{array}{l}\text { Subsistemas } \\
\text { de Recursos } \\
\text { Humanos }\end{array}$ & $\begin{array}{c}\text { Pressupostos da } \\
\text { Gestão Estratégica de } \\
\text { Recursos Humanos }\end{array}$ & $\begin{array}{c}\text { Práticas } \\
\text { observadas na } \\
\text { organização Y }\end{array}$ & $\begin{array}{l}\text { Melhorias } \\
\text { Propostas }\end{array}$ \\
\hline Recrutamento e seleção & $\begin{array}{l}\text { - atrair e selecionar pessoas com } \\
\text { perfil e comportamento que } \\
\text { contribuam para a realização da } \\
\text { missão organizacional. }\end{array}$ & $\begin{array}{l}\text { - apresenta grande } \\
\text { amplitude no processo de } \\
\text { recrutamento; } \\
\text { - deficiência no processo } \\
\text { de seleção: foca apenas } \\
\text { aspecto técnico, não o } \\
\text { comportamental; } \\
\text { - admissão de pessoas com } \\
\text { expectativas maiores do } \\
\text { que o cargo pode oferecer. }\end{array}$ & $\begin{array}{l}\text { - inclusão do fator } \\
\text { comportamental no processo de } \\
\text { seleção. }\end{array}$ \\
\hline $\begin{array}{l}\text { Treinamento e } \\
\text { desenvolvimento }\end{array}$ & $\begin{array}{l}\text { - criar um ambiente de aprendiza- } \\
\text { gem constante; } \\
\text { - melhorar o desempenho } \\
\text { individual e grupal; } \\
\text { - preparar pessoas para funções } \\
\text { futuras. }\end{array}$ & $\begin{array}{l}\text { - não existe um programa } \\
\text { formal de treinamento para } \\
\text { servidores recém admitidos. } \\
\text { - os treinamentos ocorrem } \\
\text { de forma esporádica; } \\
\text { - visa aumentar o } \\
\text { desempenho no cargo } \\
\text { atual. }\end{array}$ & $\begin{array}{l}\text { - adoção de um programa de } \\
\text { integração para funcionários } \\
\text { recém admitidos; } \\
\text { - criação de um programa } \\
\text { permanente de capacitação e de } \\
\text { desenvolvimento dos servidores; } \\
\text { - treinamentos específicos para } \\
\text { gestores sobre temas como } \\
\text { legislação, liderança, mediação } \\
\text { de conflitos, motivação, etc.; } \\
\text { - criação de um ambiente de } \\
\text { aprendizagem e melhoria } \\
\text { contínua; } \\
\text { - preparar servidores para o } \\
\text { desempenho de funções futuras. }\end{array}$ \\
\hline
\end{tabular}

Quadro 1: Composição dos fatores

Fonte: Elaborado pelos autores 


\begin{tabular}{|c|c|c|c|}
\hline $\begin{array}{l}\text { Subsistemas } \\
\text { de Recursos } \\
\text { Humanos }\end{array}$ & $\begin{array}{c}\text { Pressupostos da } \\
\text { Gestão Estratégica de } \\
\text { Recursos Humanos }\end{array}$ & $\begin{array}{c}\text { Práticas } \\
\text { observadas na } \\
\text { organização Y }\end{array}$ & $\begin{array}{l}\text { Melhorias } \\
\text { Propostas }\end{array}$ \\
\hline Remuneração & $\begin{array}{l}\text { - fidelização através de uma } \\
\text { política salarial equivalente ao setor } \\
\text { privado; } \\
\text { - remuneração ligada ao } \\
\text { desempenho individual, grupal ou } \\
\text { organizacional. }\end{array}$ & $\begin{array}{l}\text { - não tem programa de } \\
\text { remuneração por metas ou } \\
\text { desempenho; } \\
\text { - não tem gratificação } \\
\text { para qualificação; } \\
\text { - focado na estrutura dos } \\
\text { cargos; } \\
\text { - remuneração reajustada } \\
\text { com tempo de serviço. }\end{array}$ & $\begin{array}{l}\text { - remuneração atrelada ao } \\
\text { desempenho individual e ao } \\
\text { resultado organizacional; } \\
\text { - adicional de incentivo a } \\
\text { qualificação; } \\
\text { - equivalência ao setor privado; } \\
\text { - promoção de prêmios } \\
\text { (pecuniários ou não) pelo } \\
\text { resultado alcançado. }\end{array}$ \\
\hline $\begin{array}{l}\text { Avaliação de } \\
\text { desempenho }\end{array}$ & $\begin{array}{l}\text { - identificação das deficiências a } \\
\text { serem melhoradas para atender as } \\
\text { necessidades organizacionais; } \\
\text { - planejamento mútuo do } \\
\text { desempenho a ser alcançado; } \\
\text { - orientação para resultados. }\end{array}$ & $\begin{array}{l}\text { - planejamento mútuo dos } \\
\text { fatores de desempenho; } \\
\text { - metodologia inadequa- } \\
\text { da: a linguagem } \\
\text { apresentada é bastante } \\
\text { técnica; } \\
\text { - utilizada para dar } \\
\text { embasamento às } \\
\text { promoções; } \\
\text {-feedback insuficiente. }\end{array}$ & $\begin{array}{l}\text { - Utilizar uma didática adequada } \\
\text { que atenda as especificidades de } \\
\text { cada cargo e fornecer feedback ao } \\
\text { servidor sobre seu desempenho; } \\
\text { - utilizar a avaliação para } \\
\text { identificar necessidades de } \\
\text { treinamento; } \\
\text { - incluir a avaliação pelos seus } \\
\text { pares. }\end{array}$ \\
\hline Plano de carreira & $\begin{array}{l}\text { - identificação das competências } \\
\text { para o crescimento na organização. } \\
\text { - gestão por competências; } \\
\text { - programas de promoção e } \\
\text { desenvolvimento de carreiras; } \\
\text { - perspectiva de crescimento, } \\
\text { funciona como fator motivador. }\end{array}$ & $\begin{array}{l}\text { - simplesmente não possui } \\
\text { plano de carreira; } \\
\text { - existe promoção, que } \\
\text { consiste apenas no } \\
\text { reenquadramento salarial, } \\
\text { não propondo novas } \\
\text { tarefas, responsabilidades } \\
\text { ou desafios. }\end{array}$ & $\begin{array}{l}\text { - formalização de um plano de } \\
\text { gestão de competências, } \\
\text { formalizando quais são as } \\
\text { competências necessárias para } \\
\text { assumir cargos estratégicos dentro } \\
\text { da instituição; } \\
\text { - implantação de banco de } \\
\text { talentos; } \\
\text { - identificação e divulgação dos } \\
\text { caminhos a percorrer e quais os } \\
\text { requisitos necessários. }\end{array}$ \\
\hline Rotina de pessoal & $\begin{array}{l}\text { - informatização; } \\
\text { - sistema de informações. }\end{array}$ & $\begin{array}{l}\text { - registros funcionais e } \\
\text { financeiros manuais, pouco } \\
\text { informatizados; } \\
\text { - não possui sistema de } \\
\text { informações para dar } \\
\text { suporte a decisões } \\
\text { estratégicas; } \\
\text { - controle de freqüência } \\
\text { automatizado. }\end{array}$ & $\begin{array}{l}\text { - informatização da rotina de } \\
\text { pessoal; } \\
\text { - implantação de um sistema } \\
\text { integrado sobre a vida funcional } \\
\text { e financeira dos servidores; } \\
\text { - disponibilização do sistema } \\
\text { para acesso aos servidores, onde } \\
\text { possam acompanhar e solicitar } \\
\text { serviços relacionados à vida } \\
\text { profissional. }\end{array}$ \\
\hline
\end{tabular}

Quadro 1: Composição dos fatores

Fonte: Elaborado pelos autores 
Desse modo, acredita-se que se a organização adotar algumas das melhorias propostas do Quadro 1 estará caminhando em direção a uma gestão pública mais eficiente e eficaz (GONZÁLEZ; GIDUMAL, 2009), o que resultaria em melhores resultados organizacionais, culminando em benefícios para os cidadãos.

\section{Considerações Finais}

Pouca atenção tem sido dada à avaliação dos efeitos da gestão de Recursos Humanos sobre o desempenho das organizações públicas (WILLIAMS, 2004) e na organização estudada, isso não é diferente.

No setor público, inúmeros fatores como regulamentação, dependência de instâncias superiores, falta de alinhamento aos aspectos estratégicos, falta de autonomia, entre outras características, fazem aflorar a burocracia nos processos relacionados à gestão de pessoas. Apesar das dificuldades ou limitações enfrentadas pelo setor público, os gestores da organização estudada podem adotar uma postura mais estratégica, introduzindo modernas práticas para atingir objetivos organizacionais conforme destacaram FairBrother (1996), Boyne, Jenkins e Poole (1999), Seabra (2001), Willians (2004), Lavelle (2005) e Ayres (2006), González e Gidumal (2009), o que representaria uma evolução nos resultados da área de Recursos Humanos.

A falta de uma política que integre os servidores com a missão organizacional nos demonstra que a organização $\mathrm{Y}$ apresenta uma visão mecanicista em relação aos seus empregados e apesar de usar o termo "Recursos Humanos" na composição do nome da área, de muitos entrevistados falarem em "estratégia". Pelas características observadas, a área de Recursos Humanos na organização é um típico departamento de pessoal, operacionalizando a rotina administrativa.

Pesquisas futuras poderiam analisar como as propostas aqui registradas para a melhoria da gestão de recursos humanos em organizações públicas poderiam gerar resultados organizacionais superiores, por meio de surveys e outros estudos de caso. 


\section{Towards a Strategic Human Resource Management? Case Study at a Public Organization in São Paulo}

\section{Abstract}

This article aims to analyze the use of human resource practices in a public organization in Sao Paulo. In this paper we try to answer the question: is the human resource management in the organization $\mathrm{Y}$ compatible with the new strategic issues this area? We adopted a qualitative approach, through case study. The primary data were obtained through interviews and secondary data were obtained through analysis of information and documents provided by the studied organization as well as direct observation of organizational routine. The results indicate that, despite the organization uses the term strategic human resources management, it is focused on legal and operational issues. The human resource practices are not integrated and some practices do not exist (career plan and training). Thus, it is believed that if the organization adopts some of the improvements suggested in this article, it will be walking toward a more strategic human resource management entering in the new public management.

Key-words: Human Resources Management. Public sector. Strategic management.

\section{Referências}

AHMED, F.; KAZMI, A. Historical evolution of strategic human resource management. Malaysian Management Review, Asia, v. 34, n. 1, 1999.

ALBERT, M.; SILVERMAN, M. Making management philosophy a cultural reality, part 2: design human resources programs accordingly. Personnel, UK, v. 61, n. 2, p. 28-35, mar./abr., 1984.

ALBUQUERQUE, L. G. A Gestão estratégica de pessoas. In: FLEURY, M. T. L. (Org.). As pessoas na organização. 9. ed. São Paulo: Gente, 2002. p. 35-49.

ARAÚJO, L. C. G. de. Gestão de pessoas: estratégias e integração organizacional. São Paulo: Atlas, 2006. 
AYRES, C. B. A administração pública brasileira e as vicissitudes do paradigma de gestão gerencial. Sociologia, Problemas e Práticas, n. 51, 2006, p. 29-52. Disponível em: <https://repositorio.iscte.pt/bitstream/10071/ 362/1/Soc51Carlos.pdf>. Acesso em: 23 abr. 2008.

BATEMAN, T. S.; SNELL, S. A. Administração: construindo vantagens competitivas. Trad. Celso A. Rimoli. São Paulo: Atlas, 1998.

BATISTA, F. F. (Coord.) Passos para o Gerenciamento Efetivo de Processos no Setor Público: Aplicações Práticas. Instituto de Pesquisa Econômica Aplicada. IPEA. Brasília: jun. 1996.

BELOUT, A.; DOLAN, S. L.; SABA, T. Trends and emerging practices in human resource management - The Canadian scene. International Journal of Manpower, UK, v. 22, n. 3, 2001, p. 207-215.

BORGES-ANDRADE, J. E. Desenvolvimento de medidas em avaliação de treinamento. Estudos de Psicologia, Brasil, v. 7 (Número especial), 2002, p. 31-43.

BORGES, M.; HOPPEN, N.; LUCE, F. B. Information technology impact on market orientation in e-business. Journal of Business Research, USA, v. 62, 2009, p. 883-890.

BOYNE, G.; JENKINS, G.; POOLE, M. Human resource management in the public and private sectors: an empirical comparison. Public Administration, USA, v. 77, n. 2, 1999. p. 407-420.

$\mathrm{CHOW}, \mathrm{I}$. H. The impact of institutional context on human resource management in three Chinese societies. Employee Relations, UK, v. 26, n. 6, 2004, p. 626-642.

DAFT, R. L. Administração. 4. ed. Trad. Fernando Gastaldo Morales; Rio de Janeiro: LTC, 1999.

DESSLER, G. Administração de Recursos Humanos. 2. ed. Tradução Cecília Leão Oderich. São Paulo: Pearson Prentice Hall, 2003.

DUTRA, J. S. A gestão de carreira. In.: FLEURY, M. T. L. (Org.). As pessoas na organização. 9. ed. São Paulo: Gente, 2002. p. 99-114. 
EBOLI, M. O desenvolvimento das pessoas e a educação corporativa. In: FLEURY, M. T. L. (Org.). As pessoas na organização. 9. ed. São Paulo: Gente, 2002. p. 185-216.

EISENHARDT, K. M. Building Theories from Case Study Research. The Academy of Management Review, USA, v. 14, n. 4, 1989, p. 532-550.

FAIRBROTHER, P. Trade unions and human resource management in Britain: case study evidence from the public sector, utilities and manufacturing.

Employee Relations, UK, v. 18, n. 6, 1996, p.10-27.

FISCHER, A. L. Um resgate conceitual e histórico dos modelos de gestão de pessoas. In: FLEURY, M. T. L. (Org.). As pessoas na organização. 9. ed. São Paulo: Gente, 2002. p. 11-33.

FRANÇA, A. C. L; ARELLANO, E. B. Os processos de recrutamento e seleção. In: FLEURY, M. T. L. (Org.). As pessoas na organização. 9. ed. São Paulo: Gente, 2002. p. 63-72.

GAETANI, F; BAGGIO, S. B. Capacitação e desenvolvimento organizacional no setor público: entre "salgar carne podre" ou o "messianismo" dos recursos humanos. Anais.... II Congreso Internacional del CLAD sobre la Reforma del Estado y de la Administración Pública, Isla de Margarita, Venezuela, 14-18 de octubre 1997.

GIL, A. C. Gestão de pessoas: enfoque nos papéis profissionais. São Paulo: Atlas, 2006.

2007.

. Métodos e Técnicas de Pesquisa Social. 5. ed. São Paulo: Atlas,

GODOY, A. S. Introdução à pesquisa qualitativa e suas possibilidades. Revista de Administração de Empresas. São Paulo, v. 35, n. 2, p. 57-63, abr. 1995.

GONZÁLEZ, S. M.; GIDUMAL, J. B. Good moves, mistakes and unexpected events in an initiative to improve public management in the ICT service provision at a university. International Review of Administrative Sciences, USA, v. 75, n. 2, 2009, p. 271-291.

HARRIS, P. R. Human resource trends for European leaders. European Business Review, UK, v. 99, n. 1, 1999, p. 55-58. 
HESKETH, A.; FLEETWOOD, S. Beyond measuring the human resource management-organizational performance link: applying critical realist metatheory. Organization, UK, v. 13, 2006, p. 677-700.

HIPÓLITO, J. A. M. Sistema de Recompensas: uma abordagem atual. In: FLEURY, M. T. L. (Org.). As pessoas na organização. 9. ed. São Paulo: Gente, 2002. p. 87-98.

HIPÓLITO, J. A. M.; REIS, G. G. A avaliação como instrumento de gestão. In: FLEURY, M. T. L. (Org.). As pessoas na organização. 9 ed. São Paulo: Gente, 2002. p. 73-86.

HUSELID, M. A.; JACKSON, S. E.; SCHULER, R. S. Technical and estrategic human resource management effectiveness as determinants of firm performance. Academy of Management Journal, USA, v. 40, n. 1, 1997, p. 171-188.

JABBOUR, C. J. C.; SANTOS, F. C. A. The central role of human resource management in the search for sustainable organizations. The International Journal of Human Resource Management, UK, v. 19, n. 12, 2008, p. 2133-2154.

LAVELLE, J. It's all about context and implementation some thoughts prompted by: unlocking the human potential for public sector performance - The united nations world public sector report 2005. Public Personnel Management, USA, v. 35, n. 3, 2006, p. 217-228.

LIEBSCHER, P. Quantity with quality? Teaching quantitative and qualitative methods in a LIS Master's program. Library Trends, USA, v. 46, n. 4, 1998, p. 668-680.

LLEWELLYN, S.; NORTHCOTT, D. The "singular view" in management case studies qualitative research in organizations and management. Qualitative Research in Organizations and Management: An International Journal, UK, v. 2, n. 3, 2007, p. 194-207.

KHATRI, N. Emerging issues in strategic HRM in Singapore. International Journal of Manpower, UK, v. 20, n. 8, 1999, p. 516-529.

KOGA, N. M. Gestão de pessoas na administração pública japonesa. Ensaio. Revista do Serviço Público, Brasília, ano 58, n. 1, jan./mar., 2007, p. 97-106. 
MACKAY. L. The personnel function in the universities of northern England. Personnel Review, v. 24, n. 7, 1995, p.41-53.

MARCONI, N. Políticas integradas de recursos humanos para o setor público. In: Biblioteca Virtual TOP sobre Gestión Pública. Buenos Aires: 2003. Disponível em: www.top.org.ar/publicac.htm. Acesso em: 20 abr. 2008.

MARRAS, J. P. Administração de recursos humanos: do operacional ao estratégico. 11. ed. São Paulo: Futura, 2000.

MARTINS, G. A. Estudo de caso: uma reflexão sobre a aplicabilidade em pesquisas no Brasil. Revista de Contabilidade e Organizações, Ribeirão Preto, v. 2, n. 2, jan./abr., 2008, p. 9-18.

MIGUEL, P. A. C. Estudo de caso na engenharia de produção: estruturação e recomendações para sua condução. Produção, São Paulo, v. 17, n. 1, jan./abr. 2007, p.216-229.

MILKOVICH, G. T.; BOUDREAU, J. W. Administração de recursos humanos. São Paulo: Atlas, 2006.

MOTHERSELL, W. M., MOORE, M. L.; FORD, J, K,; FARREL, J. Revitalizing human resources management in state government: moving from transactional to transformational HR professionals in the State of Michigan. Public

Personnel Management, USA, v. 37, n. 1, 2008, p. 77-97.

NOGUEIRA, R. P.; SANTANA, J. P. Gestão de recursos humanos e reformas do setor público: tendências e pressupostos de uma nova abordagem. 2001. Disponivel em: <http://www.opas.org.br/rh/ areas_det.cfm?id_doc $=110 \& i d \_a r e a=1>$. Acesso em: 22 abr. 2008.

PABLOS, P. O.; LYTRAS, M. D. Competencies and human resource management: implications for organizational competitive advantage. Journal of Knowledge Management, USA, v. 12, n. 6, 2008, p. 48-55.

PATTON, M. G. Qualitative Research and Evaluation Methods, 3. ed. Thousand Oaks, CA: Sage, 2002.

ROBBINS, S. P.; DECENZO, D. A. Fundamentos de administração: conceitos essenciais e aplicações. 4. ed. Tradução Robert Brian Taylor, Revisão técnica Reinaldo O. da Silva. São Paulo: Pearson Prentice Hall, 2004. 
ROKNUZZAMAN, M. Status of human resource management in public university libraries in Bangladesh. The International Information \& Library Review, UK, v. 39, 2007, p. 52-61.

SAMMARTINO, W. A integração do sistema de gestão de Recursos Humanos com as estratégias organizacionais. 2002. Tese (Doutorado) Programa de Pós-Graduação em Administração da Faculdade de Economia, Administração e Contabilidade da Universidade de São Paulo, São Paulo. 2002.

SANTOS, O. B. Recrutamento de pessoal. 1973. In: FRANÇA, A. C. L.; ARELLANO, E. B. Os processos de recrutamento e seleção. In: FLEURY, M. T. L. (Org.). As Pessoas na Organização. 9. ed. São Paulo: Gente, 2002. p. 63-72.

SEABRA, S. N. A nova administração pública e mudanças organizacionais. Revista de Administração Pública. 4. ed. Rio de Janeiro, jul/ago, 2001. p. 19-43. Disponível em: <http://www.ebape.fgv.br/academico/asp/ dsp_rap_resumos.asp?cd_artigo $=639>$. Acesso em: 14 abr. 2008.

SCHULER, R. S.; JACKSON, S. E. Linking competitive strategies with human resource practices. Academy of Management Executive, USA, v. 1, n. 3, 1987, p. 207-220.

STONER, J. A. F.; FREEMAN, R. E. Administração. Trad. Alice Alves Calado. 5. ed. Rio de Janeiro: LTC, 1999.

TÜRK, K.; ROOLAHT, T. appraisal and compensation of the academic staff in Estonian public and private universities: a comparative analysis. TRAMES, USA, 2007, v. 11, n. 2, 2007, p. 206-222.

WILLIAMS, J. G. The effects of 'high commitment' HRM practices on employee attitude: the views of public sector workers. Public Administration, USA, v. 82 , n. 1,2004, p.63-81.

WORLAND, D.; MANNING, K. Strategic human resource management and performance. Working Paper Series. Victoria University. 2005.

YEGANEH, H.; SU, Z. An examination of human resource management practices in Iranian public sector. Personnel Review, USA, v. 37, n. 2, 2008, p. 203-221.

VERMA, S.; DEWE, P. Valuing human resources: perceptions and practices in UK organizations. Journal of Human Resource Costing \& Accounting, UK, v. 12, n. 2, 2008, p. 102-123. 